\title{
miR-128-3p serves as an oncogenic microRNA in osteosarcoma cells by downregulating ZC3H12D
}

\author{
MAOSHU ZHU ${ }^{1 *}$, YULONG WU ${ }^{2 *}$, ZHAOWEI WANG ${ }^{3}$, MINGHUA LIN $^{4}, \mathrm{BIN} \mathrm{SU}^{5}$, \\ CHUNYANG LI ${ }^{6}$, FULONG LIANG ${ }^{7}$ and XINJIANG $\mathrm{CHEN}^{6}$ \\ Departments of ${ }^{1}$ Central Laboratory, ${ }^{2}$ Urinary Surgery, ${ }^{3}$ Gynecology, ${ }^{4}$ Pathology, ${ }^{5}$ Pharmacy, ${ }^{6}$ Orthopedics \\ and ${ }^{7}$ Neurology, The Fifth Hospital of Xiamen, Xiang'an, Xiamen, Fujian 361000, P.R. China
}

Received August 30, 2019; Accepted November 24, 2020

DOI: $10.3892 / \mathrm{ol} .2020 .12413$

\begin{abstract}
Osteosarcoma is the second leading cause of cancer-associated mortality worldwide in children and adolescents. ZC3H12D has been shown to negatively regulate Toll-like receptor signaling and serves as a possible tumor suppressor gene. MicroRNAs (miRNAs/miRs) are known to play an important role in the proliferation of human osteosarcoma cells. However, whether miRNAs can affect tumor development by regulating the expression of ZC3H12D has not yet been investigated. The aim of the present study was to investigate the role of miR128-3p in regulating ZC3H12D expression, as well as its function in tumor cell proliferation, apoptosis, and metastasis. Reverse transcription-quantitative PCR, western blotting and dual luciferase reporter assays were performed to analyze the regulation of $\mathrm{ZC} 3 \mathrm{H} 12 \mathrm{D}$ expression by miR-128-3p. MTT, colony formation and flow cytometry assays were also used to analyze the effect of miR-128-3p on cell proliferation and apoptosis. A wound healing assay was performed to investigate the cell migration ability. The results demonstrated that miR-128-3p directly targeted ZC3H12D and downregulated its expression, thereby promoting cell proliferation and migration. miR-128-3p overexpression also improved resistance to cisplatin in MG-63 and 143B cell lines, supporting the hypothesis that miR-128-3p may function as an oncogene in osteosarcoma cells. The potential clinical significance of miR-128-3p as a biomarker and therapeutic target provides rationale for further investigation into the
\end{abstract}

Correspondence to: Mr. Fulong Liang, Department of Neurology, The Fifth Hospital of Xiamen, 101 Min'an Road, Xiang'an, Xiamen, Fujian 361000, P.R. China

E-mail: fulong_liang1964@126.com

Mr. Xinjiang Chen, Department of Orthopedics, The Fifth Hospital of Xiamen, 101 Min'an Road, Xiang'an, Xiamen, Fujian 361000, P.R. China

E-mail: chenwenlong417@126.com

*Contributed equally

Key words: osteosarcoma, ZC3H12D, miR-128-3p, proliferation, apoptosis
miR-128-3p-mediated molecular pathway and how it is associated with osteosarcoma development.

\section{Introduction}

As the most commonly occurring primary malignant bone tumor, osteosarcoma accounts for $>10 \%$ of all solid tumors worldwide (1-3). Osteosarcoma is the second leading cause of cancer-associated mortality worldwide and primarily affects young individuals, including children and adolescents $(4,5)$. Owing to advancements in surgical technology and combined therapeutic strategies, the 5-year overall survival rate of osteosarcoma has increased to $60-70 \%$ (6). However, the survival rate of patients in the advanced clinical stage and pulmonary metastases remains poor (7). Therefore, it is necessary to explore novel drugs or therapeutic strategies against this disease.

ZC3H12D, also known as TFL and p34, is a member of the $\mathrm{CCCH}$-type zinc finger-containing protein family that also includes ZC3H12A, ZC3H12B and ZC3H12C (8-10). $\mathrm{ZC} 3 \mathrm{H} 12 \mathrm{D}$, which is enriched in the lymphoid and inflamed tissues, such as lymph node, lung, and spleen (11), plays an important role in inflammation. ZC3H12D has been shown to negatively regulate Toll-like receptor signaling and suppresses both the initial inflammation storm and chronic inflammation by targeting the mRNA of cytokines as well as $N F-\kappa B$ and $c-f o s$ (12). Huang et al (11), for the first time, identified ZC3H12D as a tumor suppressor in transformed follicular lymphoma. Subsequently, other researchers have also demonstrated that overexpression of ZC3H12D inhibited cell proliferation in lung cancer (13). ZC3H12D also inhibits DNA synthesis and promotes apoptosis in lung cancer (14). The present study investigated the expression of ZC3H12D in osteosarcoma cells and analyzed its effects on the malignant behaviors of these cells.

microRNAs (miRNAs/miRs) are a family of endogenous non-coding single-stranded RNA molecules with a length of 19-22 nucleotides, which act as either oncogenes or tumor suppressors based on the function of their target genes (15). In our study, we aimed to confirm that miR-128-3p targets ZC3H12D and to identified miR-128-3p as an oncogene in osteosarcoma. The present study aimed provide novel therapeutic targets for the treatment of osteosarcoma. 


\section{Materials and methods}

Cell lines and cell culture. U2OS, 143B, Saos-2, MG-63 and hFOB1.19 cell lines were obtained from The American Type Culture Collection. Negative control cells and transfected cells were maintained in Dulbecco's modified Eagle's medium (DMEM; Xiamen Yimo Biological Technology Co., Ltd.) containing $10 \%$ fetal bovine serum, $100 \mathrm{U} / \mathrm{ml}$ penicillin, $100 \mathrm{U} / \mathrm{ml}$ streptomycin and $2 \mathrm{mM}$ l-glutamine (all Gibco; Thermo Fisher Scientific, Inc.) at $37^{\circ} \mathrm{C}$ in a $5 \% \mathrm{CO}_{2}$ atmosphere with $21 \%$ oxygen.

Predict the miRNAs targeting ZC3H12D. TargetScan (URL: http://www.targetscan.org/vert_72/) was used to screen the miRNAs targeting ZC3H12D and predict the binding site of miR-128-3p at ZC3H12D 3'untranslated region (UTR).

Plasmid constructs. The 3'UTR of the human ZC3H12D gene was amplified using 2x Phanta Master Mix (Vazyme Biotech Co., Ltd.) by PCR from the genomic DNA of MG-63. The thermocycling conditions were as follows: Initial denaturation at $95^{\circ} \mathrm{C}$ for $3 \mathrm{~min}$, followed by 30 cycles of amplification $\left(95^{\circ} \mathrm{C}\right.$ for $15 \mathrm{sec}, 60^{\circ} \mathrm{C}$ for $15 \mathrm{sec}$ and $72^{\circ} \mathrm{C}$ for $30 \mathrm{sec}$ ), and a final extension step at $72^{\circ} \mathrm{C}$ for $5 \mathrm{~min}$. The primers used were as following: 3' UTR wild-type (WT), forward, 5'-AGCTCG CTAGCCTCGAGGGGACCAACACGCACTTGCAG-3' and reverse, 5'-GCATGCCTGCAGGTCGACTCAAACCAAAGC TGGATCC-3'; 3'UTR mutant (Mut), forward, 5'-TTGATT CAGCGTAATAAGACAAGTACAAAAAAAAAAG-3' and reverse, 5'-GTCTTATTACGCTGAATCAAATAAAACAGC TTTAC-3'.

The ZC3H12D 3'UTR fragment was the cloned downstream of the firefly luciferase reporter gene in the pmirGLO vector (Promega Corporation). The mutant version of the ZC3H12D 3'UTR fragment was generated by using the QuikChange II Site-Directed Mutagenesis kit (Agilent Technologies, Inc.) according to the manufacturer's instructions.

Total RNA was isolated from MG-63 cells using Total RNA Extraction Reagent (Vazyme Biotech Co., Ltd.) according to the manufacturer's instructions. Total RNA was then reversely transcribed to cDNA using the Advantage RT-for-PCR kit (cat. no. 639505; Takara Bio, Inc.) and the following protocol of $42^{\circ} \mathrm{C}$ for $30 \mathrm{~min}$ and $85^{\circ} \mathrm{C}$ for $5 \mathrm{sec}$. The cDNA of ZC3H12D was amplified using PCR with the following primers: ZC3H12D, forward, 5'-CTAGAGCTAGCG AATTCATGGAGCACCCCAGCAAGATG-3' and reverse, 5'-TCAGCGGCCGCGGATCCGGGCTTGCCCAGGGGC GCCC-3'. The vector pCDH-EF1-MCS-T2A-Puro (Xiamen Antioch Hella Biological Technology Co., Ltd.) was used for ZC3H12D-overexpression. An empty vector was used as a negative control.

Dual-luciferase reporter assay. MG-63 and 143B cells were seeded into a 24 -well plate at a density of $4 \times 10^{5} /$ well. When the cells reached 60-80\% confluence, they were co-transfected with $50 \mathrm{pmol} / \mathrm{well} \mathrm{miR}-128-3 \mathrm{p}$ mimic (or Mimic NC) and $1 \mu \mathrm{g} /$ well pmirGLO-ZC3H12D 3'UTR WT or Mut plasmid using the Exfect Transfection Reagent (Vazyme Biotech Co., Ltd.) at $37^{\circ} \mathrm{C}$. The cells were lysed using Reporter $5 \mathrm{x}$ Lysis Buffer (Promega Corporation) at $48 \mathrm{~h}$ post-transfection, and the luciferase activity was measured using the Dual-Glo Luciferase Assay system (Promega) and normalized to Renilla luciferase activity.

Transfection. The miRNA and negative control (NC) mimic and inhibitor were obtained from Guangzhou RiboBio Co., Ltd. The sequences were as following: miR-128-3p Mimic: 5'-UCACAGUGA ACCGGUCUCUUU-3'; Mimic NC: 5'-UUGUACUACACAAAAGUACUG-3'; miR-128-3p inhibitor: 5'-AAAGAGACCGGUUCACUGUGA-3' and inhibitor NC: 5'-CAGUACUUUUGUGUAGUACAA-3'. MG-63 and 143B cells were placed in $60-\mathrm{mm}$ cell culture dishes. When the cells reached $60-80 \%$ confluence, they were transfected with $200 \mathrm{pmol} / \mathrm{well} \mathrm{miR}-128-3 \mathrm{p}$ mimic (or mimic NC) or miR-128-3p inhibitor (or inhibitor NC) using the Exfect Transfection Reagent (Vazyme Biotech Co., Ltd.) at $37^{\circ} \mathrm{C}$. Overall, $4-\mu \mathrm{g}$ aliquots of the pCDH-EF1-ZC3H12D-T2A-Puro plasmid were used per well during co-transfection of the plasmid with the miR-128-3p mimic. After a $24 \mathrm{~h}$-transfection, the cells were harvested for the subsequent experiments.

Reverse transcription-quantitative (RT-q)PCR assay. Total RNA was isolated from transfected hFOB1.19, Saos-2, U2OS, MG-63 and 143B cells using the RNA Isolater Total RNA Extraction reagent (Vazyme Biotech Co., Ltd.) according to the manufacturer's instructions. cDNA of ZC3H12D was synthesized using a HiScript II 1st Strand cDNA Synthesis kit (Vazyme Biotech Co., Ltd.) and the following protocol: $50^{\circ} \mathrm{C}$ for $30 \mathrm{~min}$ and $85^{\circ} \mathrm{C}$ for $5 \mathrm{sec}$. The reverse transcription reaction for miR128-3p was performed using a miRNA 1st Strand cDNA Synthesis kit (Vazyme Biotech Co., Ltd.) and the following protocol: $50^{\circ} \mathrm{C}$ for $30 \mathrm{~min}$ and $85^{\circ} \mathrm{C}$ for $5 \mathrm{sec}$. qPCR was conducted using an iQ5 Real-Time PCR Detection system (Bio-Rad Laboratories, Inc.) with a ChamQ SYBR qPCR Master Mix kit (Vazyme Biotech Co., Ltd.). The thermocycling conditions were: $94^{\circ} \mathrm{C}$ for $3 \mathrm{~min}$, followed by $94^{\circ} \mathrm{C}$ for $15 \mathrm{sec}, 60^{\circ} \mathrm{C}$ for $20 \mathrm{sec}$ and $72^{\circ} \mathrm{C}$ for $20 \mathrm{sec}$, for 40 cycles. Each detection was carried out in triplicate. The primers used in the reverse transcription reaction and qPCR were as follows: miR-128-3p, RT:5'-GTCGTATCCAGTGCAGGGTCCGAG GTATTCGCACTGGATACGACAAAGAG-3', forward, 5'-CGCGTCACAGTGAACCGGT-3' and reverse, 5'-AGT GCAGGGTCCGAGGTATT-3'; U6, RT: 5'-CGCTTCACG AATTTGCGTGTCAT-3', forward, 5'-GCTTCGGCAGCA CATATACTAAAAT-3' and reverse, 5'-CGCTTCACGAAT TTGCGTGTCAT-3'; ZC3H12D, RT: Random primers in HiScript II 1st Strand cDNA Synthesis kit, forward, 5'-CCA GTTCTCTGCGACCCATAGT-3' and reverse, 5'-TGTCCC TGAACCAGTCAACAGC-3'; 18S rRNA, RT: Random primers in HiScript II 1st Strand cDNA Synthesis kit, forward, 5'-CGACGACCCATTCGAACGTCT-3' and reverse, 5'-CTC TCCGGAATCGAA CCCTGA-3'. Some reports have demonstrated that GAPDH is overexpressed in numerous cancer types (16-18). 18sRNA shows less variance in expression across a variety of treatment conditions compared $\beta$-actin and GAPDH (19), therefore 18sRNA was selected as the reference gene based on previous studies (20-22). ZC3H12D and miR-128-3p expression levels were quantified using the $2^{-\Delta \Delta C q}$ method and normalized to 18S rRNA and U6. 
Western blotting. The transfected hFOB1.19, Saos-2, U2OS, MG-63 and 143B cells were lysed in ice-cold RIPA buffer (Shanghai Yeasen Biotechnology Co., Ltd.). The proteins were quantified using a BCA protein assay kit (E112-01, Vazyme). In total, $20 \mu \mathrm{g}$ protein/per lane was loaded on $10 \%$ denaturing SDS-PAGE gels per lane for electrophoresis and transferred onto PVDF membranes (Roche Diagnostics). After blocking with $5 \%$ bovine serum albumin (BSA; Sigma-Aldrich; Merck KGaA) in Tris- $\mathrm{HCl}$ buffer at $28^{\circ} \mathrm{C}$ for $2 \mathrm{~h}$, the membranes were incubated with the primary antibody Anti- ZC3H12D (1:1,000; cat. no. 24991-1-AP; ProteinTech Group, Inc.) or anti-GAPDH (1:5,000; cat. no. YM3029; Immunoway; http://www.immunoway.com/) prepared in Tris- $\mathrm{HCl}$ buffer containing $5 \% \mathrm{BSA}$ at $4^{\circ} \mathrm{C}$ overnight. Next day, the membranes were washed with Tris- $\mathrm{HCl}$ buffer, followed by incubation with the corresponding secondary antibody HRP-Goat Anti-Rabbit IgG $(\mathrm{H}+\mathrm{L})(1: 5,000$; cat. no. SA00001-2; ProteinTech Group, Inc.) or HRP-goat anti-mouse $\operatorname{IgG}(\mathrm{H}+\mathrm{L})(1: 5,000$; cat. no. SA00001-1; ProteinTech Group, Inc.) at $28^{\circ} \mathrm{C}$ for $1 \mathrm{~h}$. Subsequently, the membranes were washed with Tris-HCl buffer. Protein bands were visualized using the reagent Pierce ECL (Thermo Fisher Scientific, Inc.) and a Chemo XRS + luminometer (Bio-Rad Laboratories). GAPDH was used as the loading control. Protein expression levels were quantified using the Quantity One software (Bio-Rad Laboratories).

Cell proliferation assay. After transfection, 143B and MG-63 cells were seeded into 96 -well plates at an initial density of $3 \times 10^{3}$ cells/well. The cells were stained with MTT (Shanghai Yeasen Biotechnology Co., Ltd.) at each time point for $4 \mathrm{~h}$ at $37^{\circ} \mathrm{C}$. The purple formazan was dissolved with dimethyl sulphoxide (Sigma-Aldrich; Merck KGaA). The absorbance at $490 \mathrm{~nm}$ was measured with SpectraMax Absorbance Reader (Molecular Devices). All experiments were performed in triplicates.

Colony formation assay. After transfection, 143B and MG-63 cells were seeded into 6-well plates at a density of 1,000 cells/well and maintained in DMEM containing $10 \% \mathrm{FBS}$ at $37^{\circ} \mathrm{C}$ for $7-10$ days. After most of the colonies had expanded to $>50$ cells, the cells were washed with PBS, fixed in $4 \%$ methanol at $28^{\circ} \mathrm{C}$ for $15 \mathrm{~min}$ and stained with $0.1 \%$ crystal violet (Beijing Solarbio Science \& Technology Co., Ltd.) at $28^{\circ} \mathrm{C}$ for $15 \mathrm{~min}$. The colonies were photographed and the number of them were counted using ImageJ (1.8.0; National Institutes of Health). At least three independent experiments were carried out for each assay.

Cell cycle assay. After transfection, 143B and MG-63 cells were seeded at a density of $2 \times 10^{5}$ cells per well in 6 -well plates. After $24 \mathrm{~h}$ the cells were harvested and fixed in $70 \%$ ethanol at $4^{\circ} \mathrm{C}$ overnight. The fixed cells were incubated with $0.5 \mathrm{ml}$ PBS containing $10 \mu \mathrm{g} / \mathrm{ml}$ RNase and $0.2 \%$ Triton X-100 for $30 \mathrm{~min}$ at $37^{\circ} \mathrm{C}$, then stained with $20 \mu \mathrm{g} / \mathrm{ml} \mathrm{PI}$ for $30 \mathrm{~min}$ in the dark at $28^{\circ} \mathrm{C}$. A flow cytometer Finally, the stained cells were analyzed by flow cytometry. The flow cytometer NovoCyte 1300 (ACEA Bioscience) and software NovoExpress 1.4.1 (ACEA Bioscience) were used to determine the cell cycle distribution.
Apoptosis assay. Annexin V-FITC and PI (Vazyme Biotech Co., Ltd.) were used to detect cell apoptosis by flow cytometry. After transfection, 143B and MG-63 cells were seeded into 6 -well plates at a density of $4 \times 10^{5}$ per well, followed by incubation with $20 \mu \mathrm{M}$ cisplatin at $37^{\circ} \mathrm{C}$ for $24 \mathrm{~h}$. The cells were then collected, rinsed with PBS, and stained with $200 \mu \mathrm{g} / \mathrm{ml}$ Annexin V-FITC and $30 \mu \mathrm{g} / \mathrm{ml}$ PI in the dark at $28^{\circ} \mathrm{C}$ for $10 \mathrm{~min}$. Immediately, the fluorescence was analyzed in 10,000 cells/sample using the flow cytometer NovoCyte (ACEA) and software NovoExpress 1.4.1 (ACEA). The results were expressed as the percentage of cells exhibiting early and late apoptosis relative to total cells analyzed.

Wound healing assay. After transfection, MG-63 and 143B cells were seeded into a 6 -well plate $\left(4 \times 10^{5} /\right.$ well). Once they reached $100 \%$ confluence, the wound was created using a 200- $\mu 1$ pipette tip. The cells were continuously cultured in serum-free medium for $24 \mathrm{~h}$ and observed under a light microscope at a magnification of $40 x$. Images were captured at 0 and $24 \mathrm{~h}$.

Statistical analysis. All statistical analyses were performed using SPSS software 22.0 (IBM Corp.). GraphPad Prism 5 (GraphPad Software, Inc.) was used to construct the graphs. The data are presented as the mean \pm standard deviation (SD) of three independent experiments, unless otherwise shown. Tukey's test was used to identify significant differences among multiple groups. Unpaired student's t-tests were used to compare two groups. $\mathrm{P}<0.05$ was considered to indicate a statistically significant difference.

\section{Results}

Comparison of expression levels of ZC3H12D in osteoblast and osteosarcoma cells. RT-qPCR and western blotting were used to analyze the expression of ZC3H12D in mRNA and protein levels, respectively. The results showed that both the mRNA and the protein levels of ZC3H12D were decreased in the osteosarcoma cells (U2OS, 143B, Saos-2 and MG-63) compared with those in the osteoblast cell hFOB1.19 $(\mathrm{P}<0.0001$; Fig. 1A and B). The expression level of ZC3H12D was the highest in the MG-63 and 143B cell lines, therefore these were selected for further experiments.

miR128-3p targets ZC3H12D and reduces the expression level of ZC3H12D in osteosarcoma cells. TargetScan software was used to scan possible miRNAs targeting ZC3H12D and miR-128-3p was selected as the potential miRNA (Fig. 1C). Then, a Dual-luciferase reporter assay was performed. As shown in Fig. 1D, transient co-transfection of an miR-128-3p mimic and a pmirGLO-ZC3H12D 3' UTR plasmid resulted in a notable decrease in the luciferase activity compared with the NC group in MG-63 ( $\mathrm{P}=0.0001)$ and $143 \mathrm{~B}(\mathrm{P}<0.0001)$ cells. Moreover, the regulatory effect of the miR-128-3p mimic or inhibitor on ZC3H12D expression was examined using RT-qPCR and western blotting. As shown in Fig. 1E, the mRNA levels of ZC3H12D in the MG-63 and 143B cells were markedly decreased after transfection with the miR-128-3p mimic, but increased after transfection with the miR-128-3p inhibitor (Fig. 1F), compared with those in the NC group. 

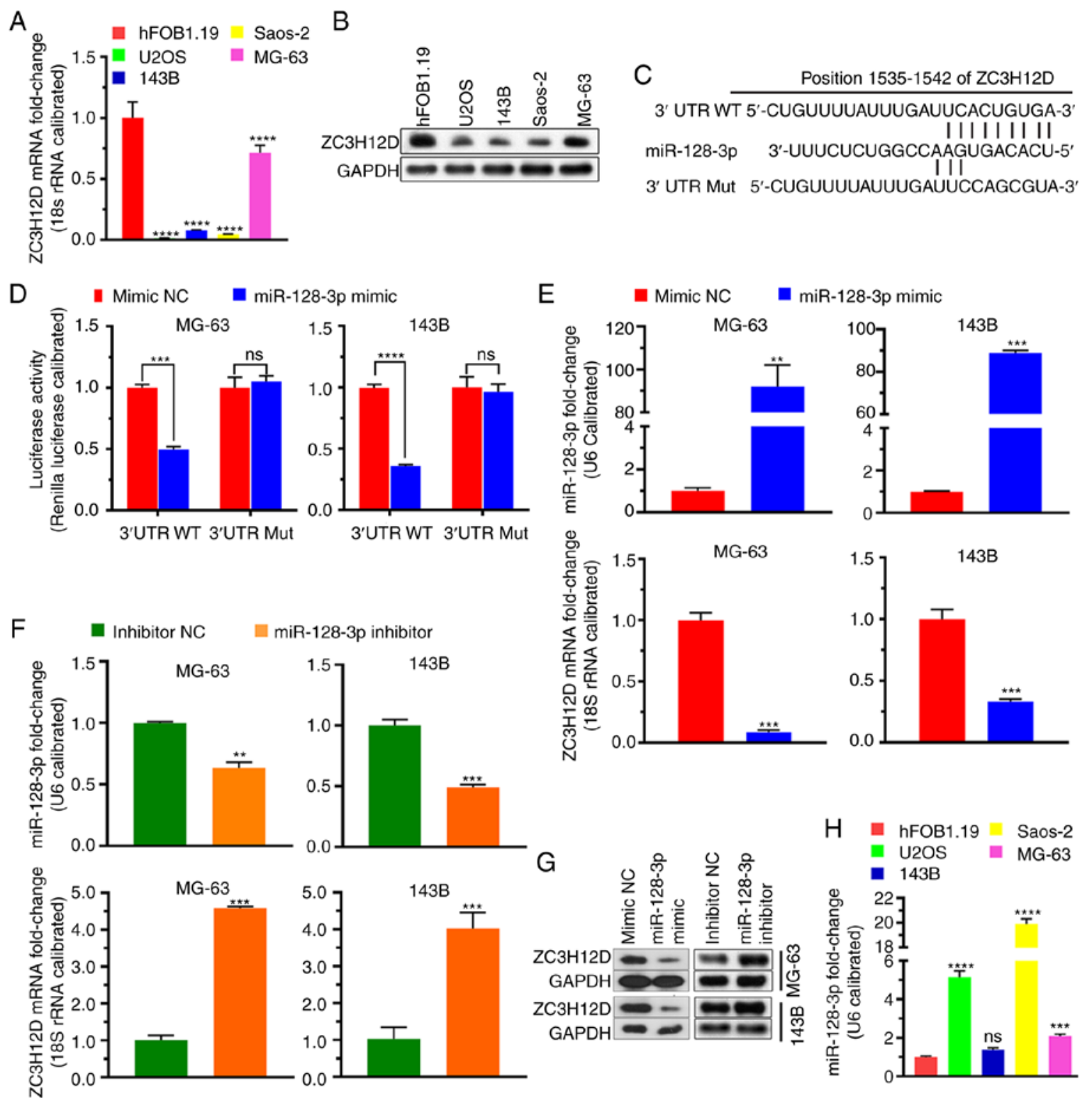

Figure 1. miR-128-3p directly targets ZC3H12D. (A) mRNA expression level of ZC3H12D was lower in osteosarcoma cells. (B) Protein expression level of ZC3H12D was lower in osteosarcoma cells. (C) miR-128-3p as the candidate miRNA targeting ZC3H12D. (D) Dual-luciferase reporter assay indicating that miR-128-3p directly targeted the 3'UTR of ZC3H12D. (E) Reverse transcription-quantitative PCR analysis showing that miR128-3p reduced the ZC3H12D mRNA level. (F) Suppression of miR-128-3p increased the ZC3H12D mRNA level. (G) Western blot analysis showing the protein expression of ZC3H12D. (H) miR-128-3p was upregulated in osteosarcoma cells. ${ }^{* *} \mathrm{P}<0.01,{ }^{* * *} \mathrm{P}<0.001$ and ${ }^{* * * *} \mathrm{P}<0.0001 \mathrm{vs.} \mathrm{hFOB1.19}$ cells, Mimic NC or inhibitor NC. miR, microRNA; UTR, untranslated region; ns, not significant; NC, negative control; WT, wild-type; Mut, mutant type.

The change in ZC3H12D protein levels was consistent with the mRNA levels. In addition, the expression of miR-128-3p was upregulated in the osteosarcoma cells, compared with that in the osteoblast cell hFOB1.19 (Fig. 1G). These findings suggested that miR128-3p directly targets ZC3H12D and downregulates its expression in osteosarcoma cells.

miR128-3p promotes the proliferation of osteosarcoma cells. The present study aimed to determine whether miR-128-3p serves as an oncogenic miRNA by targeting ZC3H12D. miR-128-3p-overexpression was induced in the MG-63 and 143B cells with or without ZC3H12D-overexpression (Fig. 2A-D). An MTT assay was performed to evaluate cell viability. As shown in Fig. 2E, the miR-128-3p mimic significantly promoted cell proliferation $(\mathrm{P}<0.001)$ compared with the Mimic NC. The results of the colony formation assay showed that the colony numbers were also significantly increased after overexpression of miR-128-3p (Fig. 2F). The number was increased from $372 \pm 24$ to $800 \pm 21$ ( $P=0.0002$, Fig. $2 \mathrm{G}$ ) for MG-63 cells and from $211 \pm 10$ to $326 \pm 15$ ( $P=0.0005$, Fig. $2 \mathrm{G}$ ) for $143 \mathrm{~B}$ cells. The effect of miR128-3p on cell cycle progression was analyzed using flow cytometry. As shown in Fig. $2 \mathrm{H}$ and $\mathrm{I}$, the miR-128-3p mimic reduced the percentage of cells in the $G_{0} / G_{1}$ phase and increased the proportion of cells in the $S$ phase in comparison with the Mimic NC. Taken together, these results indicated that miR128-3p could prevent $G_{1}$ phase arrest in MG-63 and 143B cells and promote proliferation. Moreover, ZC3H12D-overexpression reversed the effects of miR-128-3p (Fig. 2E-I). 
A

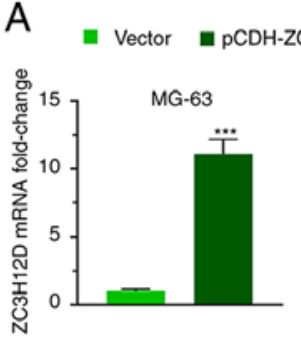

D

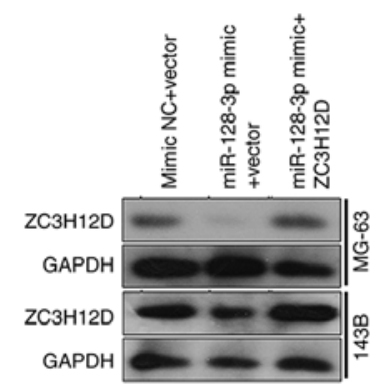

G

- Mimic NC+vector

miR-128-3p mimic+vector

miR-128-3p mimic +ZC3H12D
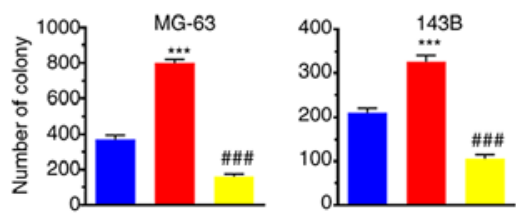

B
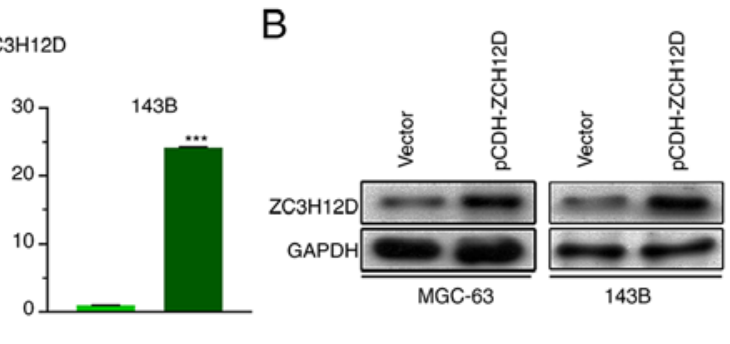

E $\rightarrow$ Mimic NC+vector

- miR-128-3p mimic+vector

- miR-128-3p mimic+ZC3H12D
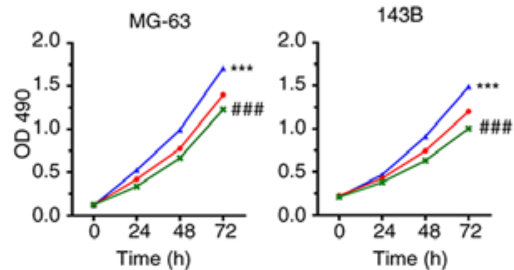

$\mathrm{H}$

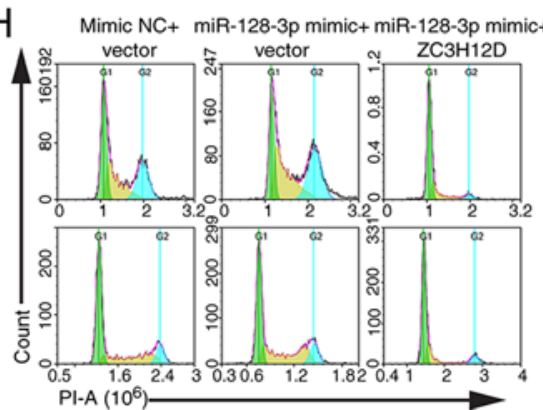

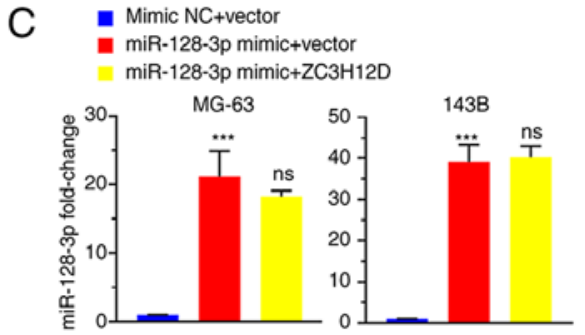

F
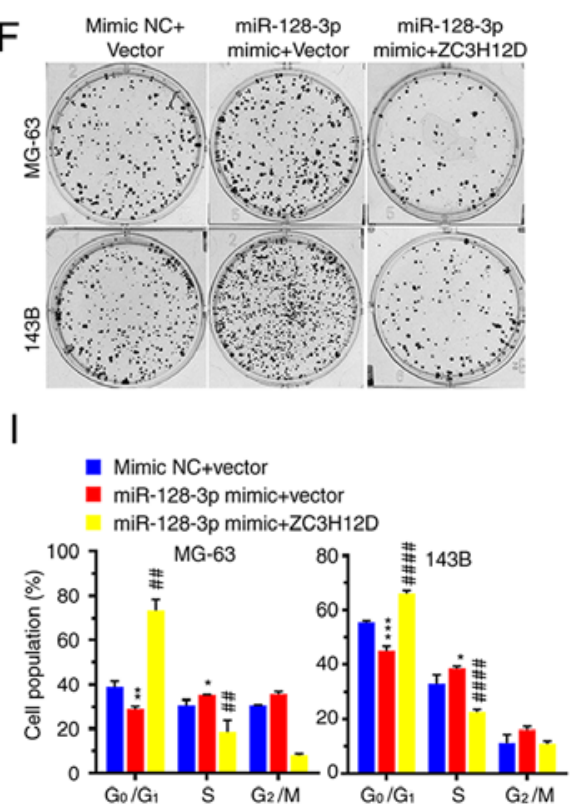

Figure 2. miR-128-3p promotes cell proliferation. (A) Analysis of the mRNA expression level of ZC3H12D after transfection with ZC3H12D plasmid. (B) Analysis of western blotting showing the protein expression level of ZC3H12D (C) Analysis of RT-qPCR showing miR-128-3p and ZC3H12D expression levels after miR-128-3p overexpression with or without ZC3H12D overexpression. (D) Analysis of western blotting showing the protein expression level of ZC3H12D (E) MTT assay showing cell viability. (F) Representative images of cell colony formation assay. (G) Histogram of colony number. (H) Representative images of cell cycle analysis using flow cytometry. (I) miR-128-3p promotes entry of cells into the $\mathrm{S}$ phase. ${ }^{*} \mathrm{P}<0.05,{ }^{* *} \mathrm{P}<0.01$ and ${ }^{* * * *} \mathrm{P}<0.001 \mathrm{vs}$. Mimic NC + vector group; ${ }^{\# \#} \mathrm{P}<0.01,{ }^{\# \# \#} \mathrm{P}<0.001$ and ${ }^{\# \# \#} \mathrm{P}<0.0001$ vs. miR-128-3p mimic + vector group. miR, microRNA; NC, negative control; ns, not significant.

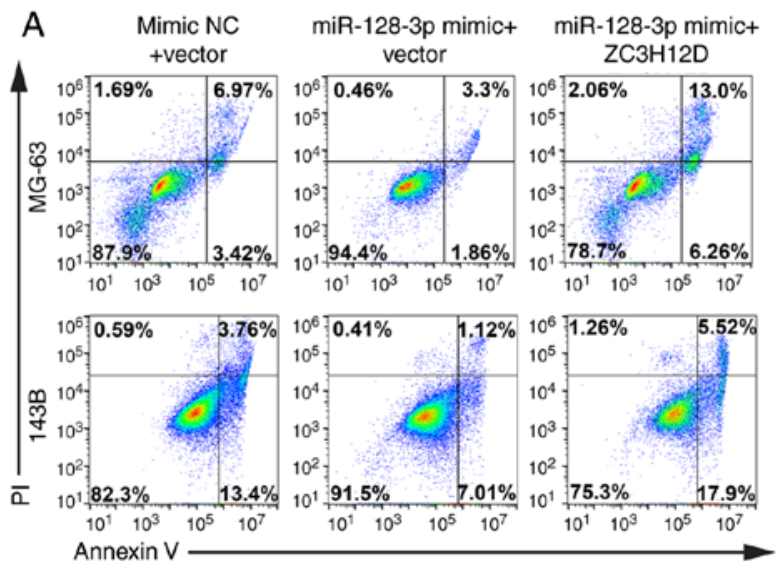

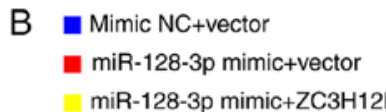

miR-128-3p mimic + ZC3H12D

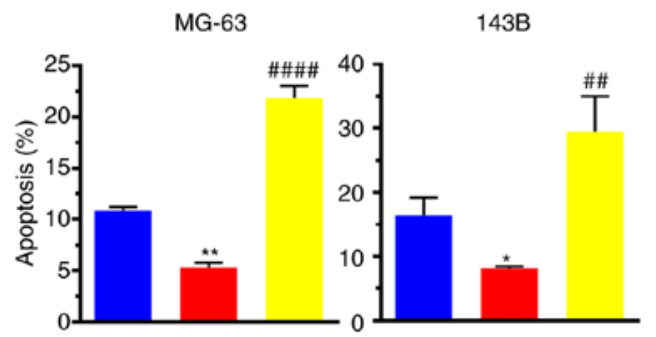

Figure 3. Apoptosis assay using flow cytometry. (A) Representative images of apoptosis analysis. (B) miR128-3p increases the resistance of osteosarcoma cells to cisplatin. ${ }^{*} \mathrm{P}<0.05$ and ${ }^{* *} \mathrm{P}<0.01$ vs. Mimic $\mathrm{NC}+$ vector group; ${ }^{\# \#} \mathrm{P}<0.01$ and ${ }^{\# \# \# t} \mathrm{P}<0.0001$ vs. miR-128-3p mimic + vector group. miR, microRNA; NC, negative control.

miR128-3p enhances the resistance of osteosarcoma cells against cisplatin. After treating the cells with $20 \mu \mathrm{M}$ cisplatin for $24 \mathrm{~h}$, flow cytometry was performed to evaluate apoptosis. The results revealed that the proportions of the apoptotic cells were $5.29 \pm 0.49$ and $8.14 \pm 0.32 \%$ for MG-63 and 143B cells overexpressing miR-128-3p, respectively. The rate of apoptosis in the mimic $\mathrm{NC}+$ vector group was higher $(10.84 \pm 0.21 \%$, $\mathrm{P}=0.0064$ and $16.42 \pm 1.58 \%, \mathrm{P}=0.0426$, respectively) (Fig. 3A and B). These data indicated that miR-128-3p improved the resistance of osteosarcoma cells to cisplatin. As expected, 

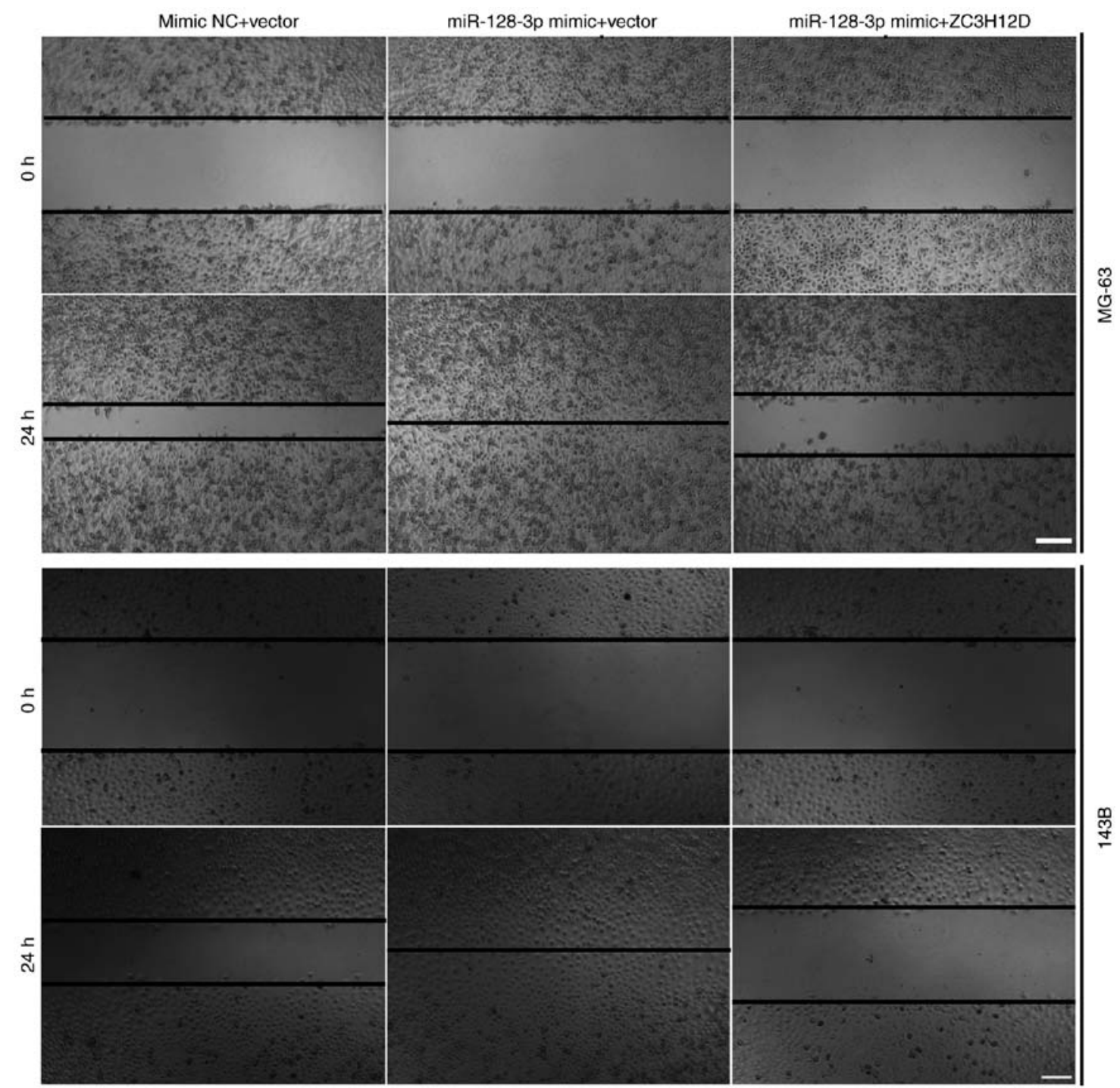

Figure 4. miR-128-3p improves the migration ability of osteosarcoma cells. Scale bars, $200 \mu \mathrm{m}$. miR, microRNA; NC, negative control.

co-overexpression of ZC3H12D eliminated the effects of miR128-3p overexpression. The percentage of apoptotic cells was increased from $5.29 \pm 0.49$ to $21.84 \pm 1.19 \%(\mathrm{P}<0.0001)$ for MG-63 cells and from $8.14 \pm 0.32$ to $29.48 \pm 5.50 \%(\mathrm{P}=0.0026)$ for $143 \mathrm{~B}$ cells (Fig. 3A and B). These results suggested that ZC3H12D increases the sensibility of osteosarcoma cells against cisplatin.

miR128-3p promotes the migration of osteosarcoma cells. To examine the effect of miR-128-3p on cell migration, a wound healing assay was performed. The results revealed that miR-128-3p improved the migration ability of the MG-63 and 143B cells (Fig. 4). Moreover, ZC3H12D overexpression reversed the miR-128-3p-induced improvement of migration ability (Fig. 4).

\section{Discussion}

ZC3H12D has identified as a tumor suppressor in transformed follicular lymphoma, lung and advanced endometrial cancer $(11,13,23)$. In the present study, it was demonstrated that ZC3H12D expression was notably decreased in osteosarcoma cell lines. Thus, it was hypothesized that ZC3H12D may also be a tumor suppressor in osteosarcoma. Next, it was confirmed that miR-128-3p directly targeted ZC3H12D and downregulated its expression, which suggested that miR-128-3p may act as an oncogenic miRNA. Finally, the effects of miR-128-3p and $\mathrm{ZC} 3 \mathrm{H} 12 \mathrm{D}$ on cellular functions in osteosarcoma cell lines were investigated and the results demonstrated that miR-128-3p indeed promotes cell proliferation and migration, but inhibits apoptosis. Moreover, ZC3H12D reversed the effects induced by miR-128-3p. The expression level of ZC3H12D was the highest in MG-63, while the expression level of miR-128-3p was the lowest in 143B, and this divergence may be explained by the fact that the expression of $\mathrm{ZC} 3 \mathrm{H} 12 \mathrm{D}$ is regulated by other molecules or miRNAs.

A miRNA can target numerous genes, and several targets of miR-128-3p, such as SAM and SH3 domain-containing protein 1, PTEN and integrin $\alpha 2$, have been reported (24-27). miR-128-3p directly targets these genes and regulates their expression, promoting cancer progression in osteosarcoma (24-27). Thus, miR-128-3p may serve as an oncogenic miRNA by downregulating not only ZC3H12D but also other tumor suppressors. However, some studies 
have reported that miR-128-3p serves as an antioncogenic miRNA in several types of cancer (27-29). For example, Huang et al (29) demonstrated that miR-128-3p suppresses the proliferation of hepatocellular cancer cells by regulating PIK3R1. miR-128-3p-overexpression sensitizes hepatocellular cancer cells to sorafenib-induced apoptosis through regulating Parkinson disease protein 7 (27). Zhao et al (28) showed that miR-128-3p overexpression suppresses breast cancer progression through targeting LIM domain kinase 1 (28). These divergences may be explained by the fact that the expression level of miR-128-3p in different types of cancer may differ, and that miR-128-3p can targets numerous genes, the expression levels of which may also be different in different cancer types. One of the limitations of present study is that we did not decrease the miR-128-3p level to observe the effect of miR-128-3p on osteosarcoma cell. Additional experiments using an miR-128-3p inhibitor to elucidate the effect of miR-128-3p on cellular function could further support our conclusion. Moreover, the objective of future research would be to find molecules downstream of the miR-128-3p/ZC3H12D pathway. In addition, the role of miR-128-3p/ZC3H12D in osteosarcoma should be studied in vivo in the next work. The present study, has found a long non-coding RNA (lncRNA) CKMT2-AS1 that exhibits antitumor activity through targeting miR-128-3p (unpublished data). We are presently constructing an animal model, which will be used to determine the function of CKMT2-AS1 in vivo, along with the effect of miR-128-3p, with the aim to elucidate the complete lncRNA/miR-128-3p/ZC3H12D axis.

Patients with localized disease have a 65-70\% 5-year survival rate (30), while those with metastasis, most commonly in lung parenchyma and distant skeletal sites, exhibit poor survival rates of $19-30 \%(31,32)$. The present study reported that miR-128-3p was highly expressed in the osteosarcoma cells, promoting cell migration, and thus it may serve as a potential therapeutic target. Suppression of miR-128-3p would inhibit the migration of osteosarcoma cells, and may increase the survival rate. Currently, the main treatment for osteosarcoma is surgery and cycles of neoadjuvant chemotherapy combinedly using three to four kinds of cytotoxic agents, such as cisplatin, doxorubicin, methotrexate and ifosfamide (30). The survival time of patients with recurrent disease with drug resistance is $\sim 1$ year (33). The present study revealed that miR-128-3p improved the resistance of osteosarcoma cells to cisplatin, and thus miR-128-3p may be a target for advancing the efficiency of chemotherapy drugs.

In conclusion, the present study demonstrated that ZC3H12D serves as a tumor suppressor in osteosarcoma cells for the first time, to the best of our knowledge. Moreover, it was also reported that the miR-128-3p/ZC3H12D axis could be a potential target for osteosarcoma treatment.

\section{Acknowledgments}

Not applicable.

\section{Funding}

The present study was supported by The Provincial Natural Science Foundation of Fujian (grant no. 2018D0022) and The
Xiamen Science and Technology Guiding Program of China (grant no. $3502 Z 20199149$ and 3502Z20209226).

\section{Availability of data and materials}

The datasets used and/or analyzed during the current study are available from the corresponding author on reasonable request.

\section{Authors' contributions}

FL and XC designed the experiments. FL, XC, MZ and YW performed the statistical analysis, interpreted the data and wrote the manuscript. MZ, YW, ZW, ML, BS and CL performed the experiments. All authors read and approved the final manuscript.

\section{Ethics approval and consent to participate}

Not applicable.

\section{Patient consent for publication}

Not applicable.

\section{Competing interests}

The authors declare that they have no competing interests.

\section{References}

1. Glover J, Krailo M, Tello T, Marina N, Janeway K, Barkauskas D, Fan TM, Gorlick R and Khanna C; COG Osteosarcoma Biology Group: A summary of the osteosarcoma banking efforts: A report from the Children's Oncology Group and the QuadW Foundation. Pediatr Blood Cancer 62: 450-455, 2015.

2. Grignani G, Palmerini E, Ferraresi V, D'Ambrosio L, Bertulli R, Asaftei SD, Tamburini A, Pignochino Y, Sangiolo D, Marchesi E, et al: Sorafenib and everolimus for patients with unresectable high-grade osteosarcoma progressing after standard treatment: A non-randomised phase 2 clinical trial. Lancet Oncol 16: 98-107, 2015.

3. Daw NC, Chou AJ, Jaffe N, Rao BN, Billups CA, Rodriguez-Galindo C, Meyers PA and Huh WW: Recurrent osteosarcoma with a single pulmonary metastasis: A multiinstitutional review. Br J Cancer 112: 278-282, 2015.

4. Di Fiore R, Guercio A, Puleio R, Di Marco P, Drago-Ferrante R, D'Anneo A, De Blasio A, Carlisi D, Di Bella S, Pentimalli F, et al: Modeling human osteosarcoma in mice through $3 \mathrm{AB}-\mathrm{OS}$ cancer stem cell xenografts. J Cell Biochem 113: 3380-3392, 2012.

5. Moreno F, Cacciavillano W, Cipolla M, Coirini M, Streitenberger P, López Martí J, Palladino M, Morici M, Onoratelli M, Drago G, et al: Childhood osteosarcoma: Incidence and survival in Argentina. Report from the National Pediatric Cancer Registry, ROHA Network 2000-2013. Pediatr Blood Cancer 64, 2017.

6. Durnali A, Alkis N, Cangur S, Yukruk FA, Inal A, Tokluoglu S, Seker MM, Bal O, Akman T, Inanc M, et al: Prognostic factors for teenage and adult patients with high-grade osteosarcoma: An analysis of 240 patients. Med Oncol 30: 624, 2013.

7. Osborne TS and Khanna C: A review of the association between osteosarcoma metastasis and protein translation. J Comp Pathol 146: 132-142, 2012.

8. Liang J, Song W, Tromp G, Kolattukudy PE and Fu M: Genome-wide survey and expression profiling of $\mathrm{CCCH}$-zinc finger family reveals a functional module in macrophage activation. PLoS One 3: e2880, 2008.

9. Liang J, Wang J, Azfer A, Song W, Tromp G, Kolattukudy PE and $\mathrm{Fu} \mathrm{M}$ : A novel $\mathrm{CCCH}$-zinc finger protein family regulates proinflammatory activation of macrophages. J Biol Chem 283: 6337-6346, 2008 
10. Minagawa K, Yamamoto K, Nishikawa S, Ito M, Sada A Yakushijin K, Okamura A, Shimoyama M, Katayama Y and Matsui T: Deregulation of a possible tumour suppressor gene, ZC3H12D, by translocation of IGK@ in transformed follicular lymphoma with t(2;6)(p12;q25). Br J Haematol 139: 161-163, 2008.

11. Huang S, Qi D, Liang J, Miao R, Minagawa K, Quinn T, Matsui T, Fan D, Liu J and Fu M: The putative tumor suppressor Zc3h12d modulates toll-like receptor signaling in macrophages. Cell Signal 24: 569-576, 2012

12. Zhang H, Wang WC, Chen JK, Zhou L, Wang M, Wang ZD, Yang B, Xia YM, Lei S, Fu EQ and Jiang T: ZC3H12D attenuated inflammation responses by reducing mRNA stability of proinflammatory genes. Mol Immunol 67: 206-212, 2015.

13. Wang M, Vikis HG, Wang Y, Jia D, Wang D, Bierut LJ, Bailey-Wilson JE, Amos CI, Pinney SM, Petersen GM, et al: Identification of a novel tumor suppressor gene p34 on human chromosome 6q25.1. Cancer Res 67: 93-99, 2007.

14. Minagawa K, Katayama Y, Nishikawa S, Yamamoto K, Sada A, Okamura A, Shimoyama M and Matsui T: Inhibition of $\mathrm{G}_{1}$ to $\mathrm{S}$ phase progression by a novel zinc finger protein $\mathrm{P} 58^{\mathrm{TFL}}$ at P-bodies. Mol Cancer Res 7: 880-889, 2009.

15. Nohata N, Hanazawa T, Kikkawa N, Mutallip M, Fujimura L, Yoshino H, Kawakami K, Chiyomaru T, Enokida H, Nakagawa M, et al: Caveolin-1 mediates tumor cell migration and invasion and its regulation by miR-133a in head and neck squamous cell carcinoma. Int J Oncol 38: 209-217, 2011.

16. Chiche J, Pommier S, Beneteau M, Mondragón L, Meynet O, Zunino B, Mouchotte A, Verhoeyen E, Guyot M, Pagès G, et al: GAPDH enhances the aggressiveness and the vascularization of non-Hodgkin's B lymphomas via NF- $\kappa \mathrm{B}$-dependent induction of HIF-1 $\alpha$. Leukemia 29: 1163-1176, 2015.

17. Liberti MV, Dai Z, Wardell SE, Baccile JA, Liu X, Gao X, Baldi R, Mehrmohamadi M, Johnson MO, Madhukar NS, et al: A predictive model for selective targeting of the Warburg effect through GAPDH inhibition with a natural product. Cell Metab 26: 648-659.e8, 2017.

18. Révillion F, Pawlowski V, Hornez L and Peyrat JP Glyceraldehyde-3-phosphate dehydrogenase gene expression in human breast cancer. Eur J Cancer 36: 1038-1042, 2000.

19. Zhu LJ and Altmann SW: mRNA and 18S-RNA coapplication-reverse transcription for quantitative gene expression analysis. Anal Biochem 345: 102-109, 2005.

20. Wang XJ, Yan ZJ, Luo GC, Chen YY and Bai PM: miR-26 suppresses renal cell cancer via down-regulating coronin-3. Mol Cell Biochem 463: 137-146, 2020.

21. Bai P, Li W, Wan Z, Xiao Y, Xiao W, Wang X, Wu Z, Zhang K, Wang Y, Chen B, et al: miR-489-3p inhibits prostate cancer progression by targeting DLX1. Cancer Manag Res 12: 2719-2729, 2020.

22. Liu L, Liu S, Duan Q, Chen L, Wu T, Qian H, Yang S, Xin D, He Z and Guo Y: MicroRNA-142-5p promotes cell growth and migration in renal cell carcinoma by targeting BTG3. Am J Transl Res 9: 2394-2402, 2017.
23. Wakahashi S, Kawakami F, Wakahashi K, Minagawa K, Matsuo K, Katayama Y, Yamada H, Matsui T and Sudo T: Transformed follicular lymphoma (TFL) predicts outcome in advanced endometrial cancer. Cancer Epidemiol Biomarkers Prev 27: 963-969, 2018.

24. Li Z, Ni J, Song D and Ding M: Regulatory mechanism of microRNA-128 in osteosarcoma tumorigenesis and evolution by targeting SASH1. Oncol Lett 15: 8687-8694, 2018.

25. Tian Z, Guo B, Yu M, Wang C, Zhang H, Liang Q, Jiang K and Cao L: Upregulation of micro-ribonucleic acid-128 cooperating with downregulation of PTEN confers metastatic potential and unfavorable prognosis in patients with primary osteosarcoma. Onco Targets Ther 7: 1601-1608, 2014.

26. Liu X, Liang Z, Gao K, Li H, Zhao G, Wang S and Fang J: MicroRNA-128 inhibits EMT of human osteosarcoma cells by directly targeting integrin $\alpha 2$. Tumour Biol 37: 7951-7957, 2016.

27. Guo XL, Wang HB, Yong JK, Zhong J and Li QH: MiR-128-3p overexpression sensitizes hepatocellular carcinoma cells to sorafenib induced apoptosis through regulating DJ-1. Eur Rev Med Pharmacol Sci 22: 6667-6677, 2018.

28. Zhao J, Li D and Fang L: MiR-128-3p suppresses breast cancer cellular progression via targeting LIMK1. Biomed Pharmacother 115: 108947, 2019.

29. Huang CY, Huang XP, Zhu JY, Chen ZG, Li XJ, Zhang XH, Huang S, He JB, Lian F, Zhao YN, et al: miR-128-3p suppresses hepatocellular carcinoma proliferation by regulating PIK3R1 and is correlated with the prognosis of HCC patients. Oncol Rep 33: 2889-2898, 2015

30. Meyers PA, Heller G, Healey JH, Huvos A, Applewhite A, Sun M and LaQuaglia M: Osteogenic sarcoma with clinically detectable metastasis at initial presentation. J Clin Oncol 11: 449-453, 1993.

31. Kager L, Zoubek A, Pötschger U, Kastner U, Flege S, Kempf-Bielack B, Branscheid D, Kotz R, Salzer-Kuntschik M, Winkelmann $\mathrm{W}$, et al: Primary metastatic osteosarcoma: Presentation and outcome of patients treated on neoadjuvant Cooperative Osteosarcoma Study Group protocols. J Clin Oncol 21: 2011-2018, 2003.

32. Kim M, Jung JY, Choi S, Lee H, Morales LD, Koh JT, Kim SH, Choi YD, Choi C, Slaga TJ, et al: GFRA1 promotes cisplatin-induced chemoresistance in osteosarcoma by inducing autophagy. Autophagy 13: 149-168, 2017.

33. Duan Z, Zhang J, Ye S, Shen J, Choy E, Cote G, Harmon D, Mankin H, Hua Y, Zhang Y, et al: A-770041 reverses paclitaxel and doxorubicin resistance in osteosarcoma cells. BMC Cancer 14: 681, 2014.

(i) (2) This work is licensed under a Creative Commons Attribution-NonCommercial-NoDerivatives 4.0 International (CC BY-NC-ND 4.0) License. 